\title{
Research on the Business Strategy of Chinese Brand in Thailand: A Case of Sichuan Cuisine
}

\author{
Ying Tang ${ }^{*}$, Zhen Chen ${ }^{2 \#, ~ Y i t o n g ~ D e n g 3 ~}$ \\ ${ }^{1}$ Business School, Lingnan Normal University, Zhanjiang, China \\ ${ }^{2}$ Guangdong Coastal Economic Belt Development Research Center, Lingnan Normal University, Zhanjiang, China \\ ${ }^{3}$ Faculty of Hospitality and Tourism Management, Macau University of Science and Technology, Macau, China \\ Email: "lingnanchenzhen@qq.com
}

How to cite this paper: Tang, Y., Chen, Z. and Deng, Y.T. (2020) Research on the Business Strategy of Chinese Brand in Thailand: A Case of Sichuan Cuisine. Open Journal of Business and Management, 8, 532-541.

https://doi.org/10.4236/ojbm.2020.82032

Received: January 27, 2020

Accepted: February 24, 2020

Published: February 27, 2020

Copyright $\odot 2020$ by author(s) and Scientific Research Publishing Inc. This work is licensed under the Creative Commons Attribution International License (CC BY 4.0).

http://creativecommons.org/licenses/by/4.0/

\begin{abstract}
The Belt and Road initiative has brought opportunities for the introduction of Chinese food into Thailand. As one of the representative cuisines in China, Sichuan cuisine coincides with the spicy taste preferences of Thai consumers. Through SWOT analysis, this research focuses on the business strategy of Sichuan Cuisine Enterprises in Thailand. The reasonable selection is the standardized production with local original taste. And the corresponding measures are discussed to improve the original communication of Sichuan Cuisine culture and the standardized management of Sichuan Cuisine Enterprises in Thailand.
\end{abstract}

\section{Keywords}

Sichuan Cuisine, Thailand Consumer, SWOT Analysis, Original Communication, Standardized Production

\section{Introduction}

Chinese food is very popular in the world. However, the overseas authentic Chinese food cooked by original Chinese enterprises is not common. On the one hand, Chinese food sold locally is more influenced by local consumers, but Chinese cooks have no time to know the local taste. On the other hand, the former Chinese enterprises generally lack the strength to operate overseas. Therefore, the Chinese who have been rooted in foreign countries for many years are more likely to undertake overseas business of Chinese food.

In recent years, with the further development of Belt and Road Initiative (BRI), Chinese enterprises have increased the investment in the relevant countries. In particular, the document "Vision and Actions on Jointly Building Silk 
Road Economic Belt and $21^{\text {st }}$-Century Maritime Silk Road" issued by the State Council of China in 2015 clearly stipulates that China needs to expand cooperation with the countries along the Belt and Road in trade and tourism. Encouraged by BRI, some Chinese catering enterprises began to operate in the countries along the Belt and Road.

Sichuan Cuisine (SC), as one of the most popular cuisines in China, has a wide range of interest groups in China and enjoys the reputation of "eating in China, taste in Sichuan" internationally. With the more and more frequent catering activities of overseas Chinese in the world, coupled with the praise of foreign friends for Chinese food, SC industry's loyal customers abroad have a guarantee of quantity and quality. This is the basis for the success of SC brand in the countries along the Belt and Road. Take Thailand, one of the core nodes of the Belt and Road as an example. In 2015, Princess Sirindhorn asked SC to appear on her 60th birthday dinner menu. This was welcomed and appreciated by the participants. Thailand's Royal preferences have a demonstration effect on ordinary people in the country, while Thailand is one of the most popular destinations in Southeast Asia for western tourists. If SC brands enter the Thai market in an appropriate way, that will increase their influence in Southeast Asia or even more.

\section{Research Idea}

This study first combines the characteristics of SC with the needs of Thai consumers, carries out SWOT analysis, and determines the feasible business strategy. Under this strategy, based on the actual situation of SC Enterprises in China, this study puts forward specific measures for SC enterprises to operate in Thailand. Through effective local promotion, SC brand can strengthen cultural exchanges between the two countries. This will also play a very good role in promoting the internationalization of SC in the future.

The promotion of SC brand in Thailand belongs to the cross regional expansion of local diet. The implementers of BRI hope that Sichuan's culture can spread along the Belt and Road taking diet as carrier. However, different regions have different acceptance of foreign cultures. If the same enterprise operates in a different place, its cognition in the public is not the same [1]. According to Zeng et al. (2013), there is a dilemma between maintaining cultural authenticity and implementing standardization in the process of cross-regional communication of catering culture [2].

A typical example is KFC Company, whose Chinese branch provides fried chicken and chips in accordance with American standards in the local market, as well as more Chinese-style products such as chicken-leg rice and chicken-roll according to the taste of Chinese consumers. At the same time of standardization, it keeps a high degree of local taste. This kind of cross regional food production mode is called Standardized Production with Local Original Taste, and its business strategy lies between the local and standardized ones [3]. Some local dishes adhere to their own characteristics in the birthplace and do not change 
with the taste of consumers in the business location, that is, Fully Original Taste Production [4]. Others claim that "the world is the same taste", that is, Fully Standardized Taste Production. In addition, some non-multinational enterprises that lack brand awareness tend to indulge consumers' tastes too much, but lose their original characteristics. For example, General Tso's Chicken, a famous Chinese dish popular in the United States, caters to American consumers' preference for sweet and crisp taste. However, this dish is not in line with the traditional taste of Chinese food, and there is no such dish in all Chinese food. This strategy neither pays attention to maintaining the origin of culture, nor to standardization. But it can exist in specific environment, which is called Heterogeneous Taste Production.

Which strategy should SC brand be promoted in Thailand? It is to solve the problem through SWOT analysis. When an enterprise enters a new competitive environment, it can examine its own capabilities and identify the external environment through this method, and then determine the appropriate development strategy. Xia (2017) once used this method to discuss SC internationalization [5]. This method can shape four strategic directions, which are in corresponding relationships with the above four production modes. See Table 1 for details. According to the actual situation of SC in Thailand, this study will choose a reasonable strategic direction.

ST strategy corresponds to the standardized production with local original taste, which is caused by severe external challenges. Even though the advantages of the brand are obvious, it is necessary to develop some standardized products while adhering to its own characteristics. Only in this way the brand can enhance its influence.

SO strategy corresponds to the fully original taste production, which will utilize its own advantages and external opportunities. Using this strategy requires the brand to have a strong comparative advantage and external appeal. The followers of the brand cannot tolerate the change of its products beyond the range. They think that it must maintain the completely original taste of the product to ensure the purity of the brand.

WT strategy, its products and operation have no characteristics, and external competition is in the downwind. Therefore, the brand must seek to develop standardized products suitable for more consumers' tastes in order to take a share in the target market. This belongs to fully standardized taste production.

Table 1. The relationship between the development strategy and the production mode of SC in Thailand.

\begin{tabular}{cc}
\hline Strategy & Production mode \\
\hline ST & Standardized production with local original taste \\
SO & Fully original taste production \\
WT & Fully standardized taste production \\
WO & Heterogeneous taste production \\
\hline
\end{tabular}


WO strategy is applicable when the advantages of the brand itself are not prominent and there are certain supporters in the local market. Using this strategy, the products under the brand can meet the taste of supporters and make a substantial change, but it is still under the slogan of the brand, for example, General Tso's Chicken. It ostensibly self advertised as Chinese food, but its main audience is the customers of the United States and Canada.

\section{SWOT Analysis}

Based on the achievements of Huang (2016), Xiao and Li (2017), combined with the field research in Sichuan and Thailand, this study conducts the following SWOT analysis [6] [7].

\subsection{Strength}

1) SC is on the way of branding.

The basis and output value of Sichuan beverage enterprises are very considerable, which is also the driving force of their own brand creation. Due to the focuses from the enterprises and the government, the development of SC has entered a standardized stage. The industry regulatory departments have successively issued various standards for SC. For example, in 2014, the Chinese SC Cooking Process Specification was formulated and implemented, which was approved by Chinese Ministry of Commerce as the industry standard subsequently. In the same year, the Tourism Administration of Sichuan Province released the compilation of English translation of SC. In October 2015, Sichuan Provincial Bureau of Quality Supervision formulated 12 standards for SC, including cooking of classic dishes, making of pasta, as well as hotpot seasoning.

2) SC has sufficient personnel training institutions.

At present, the training of SC talents not only focuses to the quality, but also the quantity. In terms of quality, the authentic skills of SC are still retained by Sichuan chefs. The industry believes that non Sichuan cooks are exaggerating in their cooking methods and do not pursue the essence of SC. Some owners of the overseas restaurants believe that the Sichuan chefs hired from home are the key of the booming of SC internationalization. In terms of quantity, the education levels of relevant majors in public colleges and universities are complete, and private colleges and universities have formed a powerful supplement.

3) The scale of overseas SC market has grown rapidly.

In recent years, there has been a steady growth of SC restaurants opening overseas, for example, Lion Tower, Huixianlou, Shuijingfang, Haidilao Hotpot and BaGuoBuYi, etc. As more and more consumers like the taste of SC, the export volume of the relevant finished products and condiments is growing rapidly, and the number of dispatched cooking technicians is growing at the same time. According to the incomplete statistics of Sichuan Provincial Department of Commerce, there were more than 200 overseas chefs in Sichuan Province every year, and their destinations covered 75 countries and regions around the world. 


\subsection{Weakness}

1) The number of talents is still insufficient to meet the overseas investment demand.

Chefs stationed abroad require the ability to fight alone. He can not only stir fry, but also cut the food. He can make cold dishes as well as hot ones. His comprehensive ability should be strong. At present, with the further growth of China's economic, there is a small gap between the salaries of highly skilled chefs at home and abroad. These chefs lack the motivation to go out. In addition to excellent cooking skills, these chefs must also receive cross-cultural training, while ensuring that foreign language clearance. There are only a few talents with the above-mentioned conditions, and they prefer to go to developed countries such as Europe and the United States, while their preference for developing countries such as Thailand is relatively low.

2) It is difficult to solve the bottleneck of raw materials and condiments export.

Due to the differences in food standards and cultures at home and abroad, the export of SC raw materials and condiments can neither fully meet the needs of opening restaurants overseas nor occupy enough consumption shares of foreigners. For example, as a famous bean paste manufacturer in Sichuan Province, Pixian Dandan Condiment Company's annual export volume is about five to six million yuans every year, far less than the domestic market. The raw materials and condiments of SC cannot be exported to overseas, which directly affects the taste of overseas Sichuan restaurants.

3) The scale management of enterprises is not enough, and the improvement of standards is still difficult.

SC enterprises have a relatively low starting point of internationalization. Its industrial level is backward and its competitiveness in the international catering market is not so strong. There is a certain gap between SC and the global mainstream food camp. In addition, the overall business process of SC industry is not in line with the international rules. The person in charge is lack of the awareness of entering the international market. The relevant studies are not enough. Moreover, there are many kinds of standards for SC, including multiple standards such as quantity standard and taste standard. Because of its complex structure, it is difficult to be known and recognized by the public.

Multinational companies are the absolute main body of international investment. The amount of overseas direct investment funds of domestic enterprises is far lower than that of multinational companies. So the technological and scale advantages of SC industry are too small, which leads to the low quality of existing SC enterprises. These enterprises often have low credit rating, weak financing ability and lack of operational liquidity.

\subsection{Opportunity}

1) The taste of local consumers in Thailand matches the characteristics of SC. 
According to the interview of some Thai students in China by Xiao Tingting and Li Yang (2017), the number of Thai students who like Chinese food accounts for $50.16 \%$, the students who don't like Chinese food accounts for $13.11 \%$, the students who think Chinese food is common accounts for $36.72 \%$ of the total [6]. It can be seen that most Thai students like Chinese food. Among the reasons for choosing Chinese food, "delicious food", "introduction by friends" and "attracted by the shape and style of food" are the top ones, accounting for $31.97 \%, 22.95 \%$ and $18.03 \%$ respectively. This shows that the internal taste and the public praise of food are still the main attraction.

In terms of Thai consumers' favorite Chinese cuisines, spicy chicken, pickled vegetable fish, cold cucumber, fish flavored shredded pork, sweet and sour pork ribs, braised chicken rice, spicy hot pot are the most frequently selected dishes for Thai students. It can be seen from the above catering preferences that SC has a broad market development prospect in Thailand. In the taste preference, there are spicy, salty, sweet and sour, which are in the forefront, accounting for $51.48 \%, 27.54 \%, 11.80 \%$ and $9.18 \%$, respectively. According to this data, Thai students are very satisfied with the taste of Chinese food, especially the characteristic spicy food. Sichuan chefs should grasp their different understanding of spicy food so as to catch the appetite of Thai consumers.

2) SC's influence is growing and overseas demand is significantly increasing.

In recent years, with the increasingly domestic competition, SC high-end brand enterprises with certain strength need to expand the overseas market and explore new sources of profit. The internal driving force of SC internationalization is gradually growing. At the 2015 International Development Forum of Chinese food, Junxian Jiang, President of China Cuisine Association, pointed out that Chinese food had sufficient international competitiveness. Its international development conditions had been mature. As an important part of Chinese food, SC had the opportunity to go abroad and improve its influence.

The color, taste and variety of SC are endless. Compared with other cuisines, it has a distinct personality; with the development of economic globalization and the deepening of cross-cultural exchanges, foreigners who know and love Chinese food and SC are steadily increasing. On amazon.com, the world's biggest online retailer, the sales volume of Chinese style stir fry hotpot keeps growing by $46 \%$ every year, while the most popular tastes are mostly related to SC, such as rattan pepper spicy pot, pickled vegetable fish pot, etc. All kinds of signs show that the market demand of SC is increasing and the market prospect is promising.

\subsection{Thread}

1) SC faces challenges from other Chinese cuisines as well as other national ones.

SC's competitors in Thailand are diversified. Some competitors are from other Chinese cuisines, such as Guangdong cuisine, Hunan cuisine and Huaiyang cuisine, which occupy part of the overseas market stably. Some homogeneous 
competitors are from the East Asian cultural circle, such as Korean Kimchi, which has successfully applied for the world heritage, and Japanese Mapo Tofu, etc. Besides, there are competitors from different overseas cuisines, such as famous French cuisine, Italian cuisine, etc.

At the same time, the enterprises of SC lack the sense of coordination and fight for themselves, which leads to the serious homogenization of products. The competition in the overseas market has evolved into a price war. The most critical point is that SC industry has not yet formed a leading enterprise, and a large number of traditional SC brands have disappeared. The authority and differentiation of SC's signature dishes are almost ignored by the international public.

2) Thailand's own food culture is not fully integrated with SC one.

Due to historical and geographical reasons, local consumers in Thailand prefer to the West in their diet, which follows the principle of harmony. The original Thai diet has a clear civilian style. Most of its raw materials are local aquatic products, vegetables or herbs. While Thailand is greatly influenced by religious culture, Thai people's diet culture has religious nature and less meat. In addition, since the $17^{\text {th }}$ century, Thai food has been influenced by Dutch, Portuguese and French food culture. Gradually, Western food began to occupy a place in Thailand, but Thailand's diet was not entirely accepting foreign food. It has improved these foreign elements and integrated them into its own characteristic culture.

3) There are some outstanding problems in the communication of SC culture.

There are obvious problems in the international communication of SC culture: the lack of foreign language media strategies specifically for foreign diners, the lack of overall international media planning scheme of SC culture, the lack of heavyweight international media to provide media platform for SC cultural products, and the lack of systematic and normative translation of SC culture in international media. On the other hand, most domestic enterprises lack management personnel who understand international catering and food marketing. Differences in overseas laws, regulations and cultural customs have restricted the speed and scale of SC restaurants expansion. If there is a lack of investigation on the market and culture of the investing country, it will often be suppressed by this country's technology. However, the problems of the enterprises' safety, standard and quality, etc. in the process of SC production increase the risk of its operation.

To sum up, the SWOT matrix of SC brand's operation in Thailand is shown in Figure 1. Based on expert advice, ST strategy, that is, the standardized production with local original taste is determined to carry out as the business strategy of SC enterprises.

\section{Suggestions on the Management of SC Brand in Thailand}

In order to apply the standardized production with local original taste to the daily business of SC enterprises, this study puts forward the measures to combine the original communication of SC culture with the standardization management of enterprises as follows. 


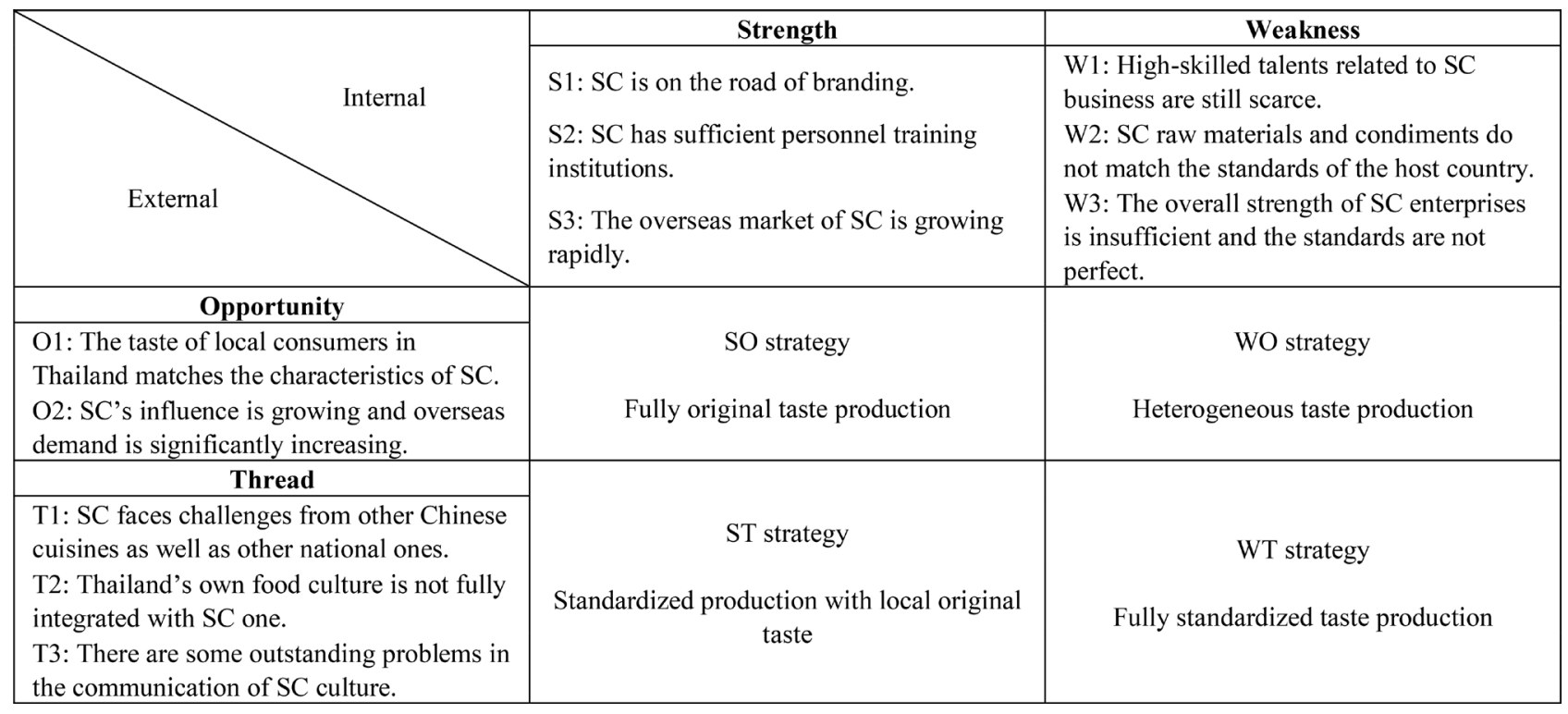

Figure 1. The SWOT matrix of SC brand's operation in Thailand.

\subsection{Original Communication of SC Culture}

1) Enhance the media vision of SC culture in Thailand

The main body of SC culture communication should have broader international communication awareness, and realize the concept transformation from food communication to food culture communication. The content of communication can not only be limited to the transmission of SC itself, but also spread the international content of SC cultural products, SC creative industries and many other aspects. SC culture, as a precious treasure of Chinese cuisine culture, should be paid attention to and accepted by Thai consumers. Furthermore, let Thai consumers understand the inclusiveness, attraction, influence and development of Chinese culture and Sichuan urban culture from the interpretation of SC culture.

The main body of SC culture communication should innovate its international communication strategy. From the perspective of the international media, we should take full advantage of Confucius institutes, overseas Sichuan Province communities, and Chinese language media to build a three-dimensional "one belt and one road" media communication system in conjunction with the print media, the digital media and the new mobile media.

2) Main strategies of digital network media

The main body of SC culture communication needs to keep pace with the times and pay attention to the feedback from the audience, and actively promote the digital network media communication. The internet integrates many kinds of media, and the same information can be presented in many ways. Therefore, the communication subject of SC culture should subvert the single-media communication mode, and gradually move towards a multi-media integration mode with the overall strategic framework. The main body of communication should give full play to the advantages of multi-media integration of the internet. We 
should actively explore the multi-channel strategy of international communication of SC culture, so as to mobilize the comprehensive cognition of various sensory organs, and spread the essence of SC culture to the world. At the same time, we should actively promote the international communication of SC culture on mobile media. Realize the real-time transmission that breaks through the limitation of time and space.

3) Standardization strategy of SC translation

The main body in charge of translation should conform to the original text, meet the psychological expectations of the host country, and refer to the national norms for the translation of food names. In March 2010, Sichuan Cuisine of China published by Sichuan Science and Technology Press is the result of the project of "translation of classic Sichuan dishes". This book reflects the inheritance of SC translation. The well-known characteristic elements in SC, such as String, Burden and Pot, are directly transliterated into "Chuan Chuan", "Dan Dan" and "Bo Bo". Similarly, the "Husband and wife lung film" is translated into "Fuqi feipian" by literal translation. In order to make foreigners understand it, it is also annotated (sliced Bee \& off Alin chili sauce). This book is a good example of the cooperation of experts, translators, media organizations and booksellers in the international communication history of SC. Based on the above, relevant departments should organize experts to compile the Thai version of the book as soon as possible, so that Thai consumers can better understand the charm of SC culture.

\subsection{Standardized Management of SC Enterprises}

1) Adhere to the branding strategy to meet the local demand in Thailand.

It is suggested to promote the innovation of dishes and ease the bottleneck of Sichuan raw materials and condiments export. For example, the development of ready to eat SC seasoning is applicable to a variety of scenes such as catering and cooking. Meishan pickles, Fuling pickles, Dandan garlic pepper and so on can move forward in the future development. At the same time, further improve the quality of traditional brewing condiments, and adjust the taste of seasoning products to suit the preferences of Thai consumers, so that the products can meet the local demand and expand the scale of trade.

2) Develop SC fast food to meet the needs of Thailand, and adhere to the customized supply of raw materials.

According to Thai consumers' preferences and aesthetic needs, improve the packaging specifications and design new packaging appearance of SC products. To create a new brand of fast food chain management, and actively promote $\mathrm{Si}$ chuan style fast food semi-finished products in line with overseas consumption habits. Strive to expand the market share of Sichuan food products in Thailand. For the key supply links of raw materials of SC, a standardized, scientific and ordered production base of raw and auxiliary agricultural products will be built. On this basis, improve the condiment production process to meet the relevant 
inspection standards of Thailand and improve the local market share.

3) In terms of personnel composition, both the recruitment and training of Sichuan chefs and Thai employees should be focused.

To establish Sichuan cuisine industry in Thailand, a large number of talents are needed. The cultivation of SC talents is the basic condition of internationalization strategy. But Sichuan restaurant employees don't mean they are all from China. The core staff of SC Enterprises, for example, the executive chef, is selected from Sichuan in principle. However, for ordinary service personnel, management and marketing personnel, it is necessary to recruit Chinese employees and Thai employees who agree with the concept of SC culture at the same time. In order to improve its standardized professional skills, it is necessary to rely on the existing general education and vocational education resources, strengthen their professional skills training, and organize and coordinate various departments to provide talent support for the operation of SC industry in Thailand through multiple channels.

\section{Acknowledgements}

This research is supported by Research project of Sichuan Cuisine Development Research Center, Philosophy and Social Sciences Key Research Base of Sichuan Province (CC16W08).

\section{Conflicts of Interest}

The authors declare no conflicts of interest regarding the publication of this paper.

\section{References}

[1] Zeng, G., Frank, G. and Henk, J.V. (2012) Dilemma of Authenticity versus Standardization: Expansion Strategies of Restaurant Groups in China. International Journal of Hospitality Management, 31, 1090-1100. https://doi.org/10.1016/j.ijhm.2012.01.006

[2] Zeng, G., Sun, S., Zhu, H., Liu, B. and Cai, X. (2013) Translocal Restaurants' Cultural Production under the Paradox of Globalization and Locality: Case Studies from Guangzhou. Scientia Geographica Sinica, 33, 291-298.

[3] Guthman, J. (2008) Bringing Good Food to Others: Investigating the Subjects of Alternative Food Practice. Cultural Geographies, 15, 425-431. https://doi.org/10.1177/1474474008094315

[4] Cook, I., Hobson, K., Hallett. L. and Guthman, J. (2010) Geographies of Food: 'Afters'. Progress in Human Geography, 35, 104-120. https://doi.org/10.1177/0309132510369035

[5] Xia, Y. (2017) New Countermeasures of Sichuan Cuisine Internationalization Based on SWOT Analysis. Sichuan Provincial Correspondence Institute for Administrators, No. 2, 7-10.

[6] Huang, X. (2016) Study on the Etiquette Difference and Its Causes in the Diet Culture between China and Thailand. Reform and Opening, No. 24, 111-113.

[7] Xiao, T.T. and Li, Y.Y. (2017) A Survey on the Preferences of Thai Students in Guangxi Province for Chinese Dishes. Peasant Adviser, No. 5, 201-202. 